\title{
EFEITO DA VELOCIDADE DE ROTAÇÃO DA FERRAMENTA NA SOLDAGEM POR FRICÇÃO E MISTURA MECÂNICA DA LIGA INCONEL 625*
}

\section{Resumo}

Guilherme Vieira Braga Lemos ${ }^{1}$ Alexandre Bellegard Farina ${ }^{2}$ Douglas Martinazzi ${ }^{3}$ Ronaldo Müller Huppes ${ }^{4}$ Luciano Bergmann ${ }^{5}$ Jorge Fernandez dos Santos ${ }^{6}$ Telmo Roberto Strohaecker ${ }^{7}$

Uma superliga a base de Níquel, popularmente conhecida como Inconel $625^{\circledR}$, foi estudada no presente trabalho. A Soldagem por Fricção e Mistura Mecânica (SFMM) aplicada a liga 625 foi realizada com velocidades de rotação da ferramenta entre 1200 a $200 \mathrm{rpm}$ e velocidade de soldagem entre 1 e $1,5 \mathrm{~mm} / \mathrm{s}$. O aporte térmico foi calculado como função dos parâmetros de soldagem empregados. Adicionalmente, análises metalográficas e de microdureza foram realizadas na seção transversal das juntas soldadas. A aplicação da soldagem no estado sólido foi efetiva e resultou em maiores valores de microdureza todas as juntas soldadas. Por outro lado, um aumento na velocidade de rotação causou um aumento do aporte térmico.

Palavras-chave: Inconel $625^{\circledR}$, Soldagem por Fricção e Mistura Mecânica, Velocidade de rotação da ferramenta, Aporte térmico.

\section{EFFECT OF THE TOOL ROTATIONAL SPEED IN FRICTION STIR WELDING OF INCONEL 625}

\section{Abstract}

Nickel base superalloy, Inconel $625^{\circledR}$, was studied in this work. The Friction Stir Welding applied to the alloy 625 was performed with tool rotational speeds ranging from 1200 to $200 \mathrm{rpm}$ and welding speed between 1 and $1.5 \mathrm{~mm} / \mathrm{s}$. The heat input was estimated as a function of welding parameters used. Additionally, metallographic and microhardness analyzes were performed in the cross section of the welded joints. The application of the solid state process was effective and resulted in increased microhardness to the welded joints. An increase in the tool rotational speed led to an increased heat input.

Keywords: Inconel $625^{\circledR}$, Friction Stir Welding, tool rotational speed, heat input.

1 Engenharia Metalúrgica, Engenheiro, Doutorando, Universidade Federal do Rio Grande do Sul, Porto Alegre, Rio Grande do Sul, Brasil.

2 Engenharia Metalúrgica, Doutor, Engenheiro Pesquisador Sr., Centro de Pesquisa e Desenvolvimento, Villares Metals S/A, Sumaré, São Paulo, Brasil.

3 Engenharia Metalúrgica, Engenheiro, Mestrando, Universidade Federal do Rio Grande do Sul, Porto Alegre, Rio Grande do Sul, Brasil.

4 Engenharia Metalúrgica, Engenheiro, Mestrando, Universidade Federal do Rio Grande do Sul, Porto Alegre, Rio Grande do Sul, Brasil.

5 Engenharia Industrial Mecânica, Engenheiro, Líder de Grupo FSW, Helmholtz-Zentrum Geesthacht, Institute of Materials Research, Materials Mechanics, Solid State Joining Processes (WMP), Germany.

6 Engenharia Metalúrgica, Doutor, Chefe de Departamento, Materials Mechanics, Solid State Joining Processes (WMP), Helmholtz-Zentrum Geesthacht GmbH, Institute of Materials Research, Geesthacht, Germany.

7 Engenharia Metalúrgica, Doutor, Professor, Universidade Federal do Rio Grande do Sul, Porto Alegre, Rio Grande do Sul, Brasil. 


\section{INTRODUÇÃO}

A liga 625 (UNS N06625), popularmente conhecida como Inconel $625^{\circledR}$, é muito usada na indústria aeroespacial, nuclear e óleo e gás devido as suas propriedades de alta resistência mecânica e excelente resistência à corrosão [1]. Além destas características, a liga 625 possui estrutura cristalina cúbica de face centrada com endurecimento por solução sólida através dos elementos Mo e $\mathrm{Nb}$ na matriz austenítica. Tradicionalmente para a construção de centrais de energia [2] ou mesmo na indústria do petróleo onde a utilização das ligas a base de níquel é comum, a união dos materiais é empregada através de processos de soldagem como eletrodo revestido, MIG, TIG, entre outros [3]. Porém é sabido que os processos de soldagem com fusão promovem uma estrutura bruta de fusão e podem resultar em problemas relacionados à segregação, porosidades, fragilização, distorção e tensões residuais [3, 4]. Além disso, na zona afetada pelo calor (ZAC) ocorre a precipitação de carbonetos ricos em $\mathrm{Cr}$, fases Laves e delta e o crescimento de grãos que tende a reduzir a resistência à corrosão [5]. Sendo assim, uma técnica alternativa de união onde as temperaturas alcançadas são suficientes para que ocorra a recristalização, sem que ocasione a fusão do material, como a soldagem por fricção e mistura mecânica (SFMM) [6] pode resultar em um aumento da resistência mecânica para a junta soldada. Um recente estudo [2] reportou melhores propriedades em juntas soldadas da liga 625 obtidas através do método SFMM quando comparadas as soldas produzidas pelo processo MIG.

A soldagem por fricção e mistura mecânica tem sido aplicada em diversas áreas da engenharia como a indústria aeroespacial, automotiva, naval, nuclear [7]. Neste processo o movimento realizado por uma ferramenta rotativa a partir de uma máquina rígida proporciona uma ação contínua de trabalho a quente e plastifica o metal no estado sólido. A junta soldada é formada por uma coluna de metal quente misturado e, à medida que a ferramenta passa, a junta soldada resfria formando uma solda livre de defeitos. Além disso, nenhum material de adição é usado, de modo que a junta tem a mesma composição que o metal de base [8]. A busca pelos melhores parâmetros de processo e a influência deles nas propriedades de juntas soldadas obtidas por SFMM tem sido o tópico de maior atenção por diversos pesquisadores [9, 10]. Gharacheh et al. [10] investigaram a influência da velocidade de rotação da ferramenta (w) e a velocidade de soldagem ( $v$ ) considerando a razão $w / V$ nas propriedades de juntas soldadas de ligas a base de Magnésio obtidas pelo método de SFMM. Eles concluíram que um aumento da razão $w / v$ leva a um aumento do aporte térmico e uma diminuição das propriedades mecânicas na zona de mistura da junta soldada.

\section{MATERIAIS E MÉTODOS}

O material de base utilizado neste estudo foi a liga de Níquel 625 (UNS N06625) na forma de chapas com 3,2 mm de espessura. A Tabela 1 mostra a composição química das chapas utilizadas.

Tabela 1. Composição química da liga de Níquel 625 (\% em massa)

\begin{tabular}{c|c|c|c|c|c|c|c|c|c|c|c}
\hline Elemento & $\mathrm{Ni}$ & $\mathrm{Cr}$ & $\mathrm{Fe}$ & $\mathrm{Mo}$ & $\mathrm{Nb}$ & $\mathrm{Co}$ & $\mathrm{Mn}$ & $\mathrm{Al}$ & $\mathrm{Ti}$ & $\mathrm{Si}$ & $\mathrm{C}$ \\
\hline Liga 625 & $\mathrm{Bal}$. & 21,7 & 4,7 & 8,6 & 3,38 & 0,03 & 0,09 & 0,13 & 0,18 & 0,18 & 0,015 \\
\hline
\end{tabular}


Inicialmente foi realizado o lixamento das chapas para remoção dos óxidos e as impurezas da superfície. Esta etapa é importante para um aumento da qualidade superficial das juntas soldadas.

O processo de SFMM foi realizado no Instituto de Pesquisas Helmholtz-Zentrum Geesthacht, na Alemanha, com uma máquina rígida em forma de pórtico equipada com servomotores e um sistema de controle automatizado. Uma ferramenta de Nitreto Cúbico de Boro Policristalino (pcBN) grau Q70 [11] foi utilizada com ombro de $25 \mathrm{~mm}$ de diâmetro e pino de $3 \mathrm{~mm}$ de comprimento. A rotação da ferramenta foi no sentido anti-horário e, sendo assim, o lado esquerdo do cordão de solda foi chamado retrocesso (LR) e o lado direito de lado de avanço (LA). A direção de soldagem seguiu à direção de laminação da chapa. Para a obtenção dos cordões de solda foi utilizado um ângulo de ataque da ferramenta de $1,5^{\circ}$ em relação à vertical. Além disso, uma atmosfera protetora de argônio foi empregada com o objetivo de minimizar a oxidação da superfície durante a soldagem.

As amostras foram cortadas por eletroerosão e as análises microestruturais seguiram as práticas convencionais de metalografia (lixamento/polimento) e, por último, atacadas com os reagentes Adler [12] ou Gliceregia [13]. A microscopia ótica foi utilizada para uma observação microestrutural geral do material de base (MB) e da seção transversal da junta soldada, enquanto a microscopia eletrônica de varredura foi empregada para análise dos precipitados e porosidades.

A resistência mecânica foi avaliada através de medidas de dureza Vickers. Os perfis de microdureza do metal de base ao longo da solda foram realizados com os seguintes parâmetros: carga $500 \mathrm{~g}$ durante 10 s e distância entre identações de 0,2 $\mathrm{mm}$. A carga das medidas foi selecionada com objetivo de evitar obtenção de medidas de microconstituintes e permitir uma avaliação global do material.

\section{RESULTADOS E DISCUSSÃO}

\subsection{Parâmetros de soldagem e aporte térmico}

Quatro juntas soldadas da liga 625 foram produzidas através do processo de soldagem por fricção e mistura mecância (SFMM) com o intuito do desenvolvimento de parâmetros de soldagem adequados. Assim, com base na aparência superficial das soldas entende-se que o parâmetro III é a melhor condição de soldagem. Portanto, com base nas juntas soldadas avaliadas no presente estudo, o aporte térmico foi calculado em função da velocidade de rotação e do torque [14] usando as seguintes Equações 1 e 2:

$$
\begin{aligned}
& H I=\frac{P}{v} \\
& P=\frac{2 \pi \Omega T}{60}
\end{aligned}
$$

Onde $\mathrm{P}$ é a potência em $\mathrm{kW}, \Omega$ é a velocidade de rotação em rev/min, t é o torque do fuso da máquina FSW em $\mathrm{Nm}$, HI é o aporte térmico $(\mathrm{J} / \mathrm{mm})$ e $v$ é a velocidade de soldagem $(\mathrm{mm} / \mathrm{seg})$. Assim os valores de aporte térmico são apresentados na Tabela 2. O aumento da velocidade de rotação de ferramenta ocasiona o aumento do aporte térmico. Entretanto, uma baixa velocidade de rotação leva a diminuição do aporte térmico e ocasiona um elevado aumento do torque. Por fim, deve ser 
lembrado que a junta soldada correspondente ao parâmetro III alcançou uma excelente aparência superficial de topo (além de um aporte térmico intermediário) sendo escolhida como melhor solda.

Tabela 1. Visão geral dos parâmetros de soldagem avaliados no trabalho.

\begin{tabular}{|c|c|c|c|c|c|c|}
\hline Parâmetros & $\begin{array}{c}\text { Velocidade } \\
\text { de } \\
\text { soldagem, } \\
\mathbf{m m} / \mathbf{s}\end{array}$ & $\begin{array}{c}\text { Rotação, } \\
\mathbf{r p m}\end{array}$ & $\begin{array}{c}\text { Superfície } \\
\text { da junta } \\
\text { soldada }\end{array}$ & $\begin{array}{c}\text { Torque, } \\
\mathbf{N} . \mathbf{m}\end{array}$ & $\begin{array}{c}\text { Profundidade } \\
\text { soldada, } \mathbf{m m}\end{array}$ & $\begin{array}{c}\text { Aporte } \\
\text { térmico, } \\
\mathbf{k J} / \mathbf{m m}\end{array}$ \\
\hline$I$ & 1 & 1200 & Média & 30 & 2,11 & 3,77 \\
\hline$I I$ & 1 & 1000 & Média & 30 & 1,83 & 3,14 \\
\hline$I I$ & 1 & 200 & Excelente & 110 & 1,81 & 2,30 \\
\hline$I V$ & 1,5 & 200 & Boa & 110 & 1,65 & 1,54 \\
\hline
\end{tabular}

\subsection{Caracterização Microestrutural}

Na Figura 1 são apresentadas micrografias da liga 625 na condição de partida (material de base). Observa-se a presença de carbonetos dos tipos $\mathrm{M}_{6} \mathrm{C}$ e $\mathrm{M}_{23} \mathrm{C}_{6}$ nos contornos de grãos, carbonitretos $M(C, N)$ e também maclas de recozimento. A identificação dos carbonetos seguiu o procedimento já descrito na literatura [13, 15]. A presença dos carbonetos indica que a liga está na condição Grau 1 da norma ASTM B446 [16] devido ao recozimento em baixa temperatura. Quando a liga 625 é recozida segundo a condição Grau 1 (norma ASTM B446) apresenta maior resistência mecânica em relação a condição solubilizada, além de ser destaque no mercado por possibilitar a redução do peso [13].

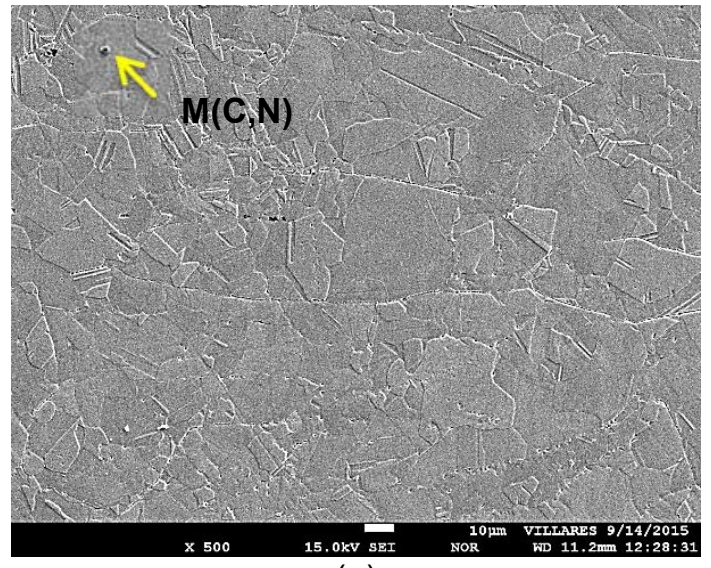

(a)

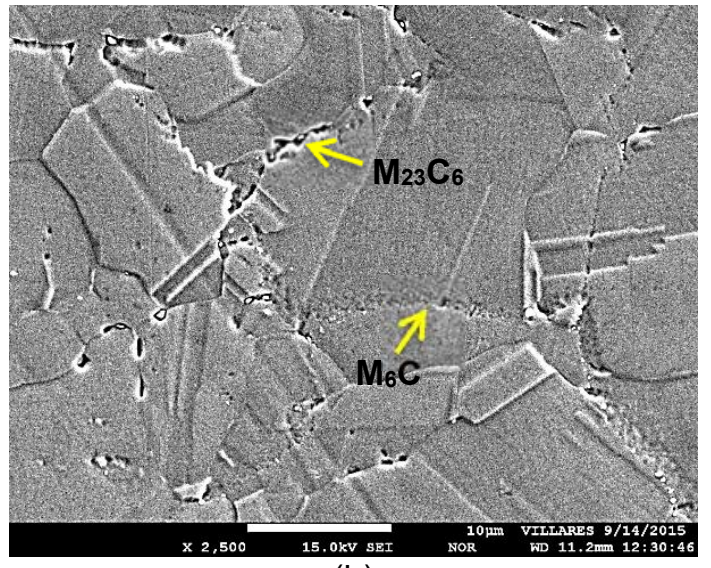

(b)

Figura 1. Material de base da Liga 625. (a) e (b) Micrografias obtidas por MEV em elétrons secundários após ataque metalográfico com reagente Glicerégia.

Nas Figuras 2 a 5 são apresentadas macrografias da seção transversal da solda e micrografias obtidas por microscópio eletrônico de varredura (MEV) em elétrons secundários da região de mistura para todos os parâmetros de soldagem estudados. De forma geral, observa-se que a soldagem por fricção e mistura mecânica acarretou no refino de grão na zona de mistura para todas as soldas quando comparadas ao material de base (Figura 1). Observa-se que os parâmetros I e II, os quais alcançaram maior aporte térmico, resultaram em maior porosidade e presença de carbonetos na microestrutura em relação aos parâmetros III e IV com menor aporte térmico. Quanto maior o aporte térmico maior a fração volumétrica de poros observados na zona de mistura. Desta forma, a caracterização indica que aportes 
térmicos menores que $2,30 \mathrm{~kJ} / \mathrm{mm}$ são aconselháveis de forma a obter uma microestrutura limpa e praticamente isenta de porosidades na soldagem, justificando, portanto, a observação da melhor qualidade do cordão de solda do parâmetro III.

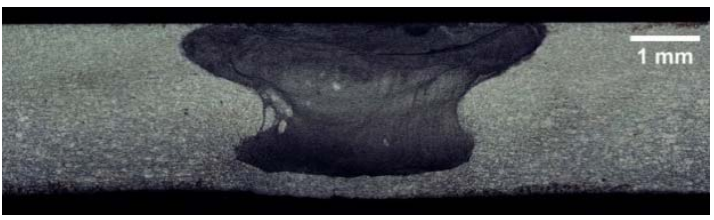

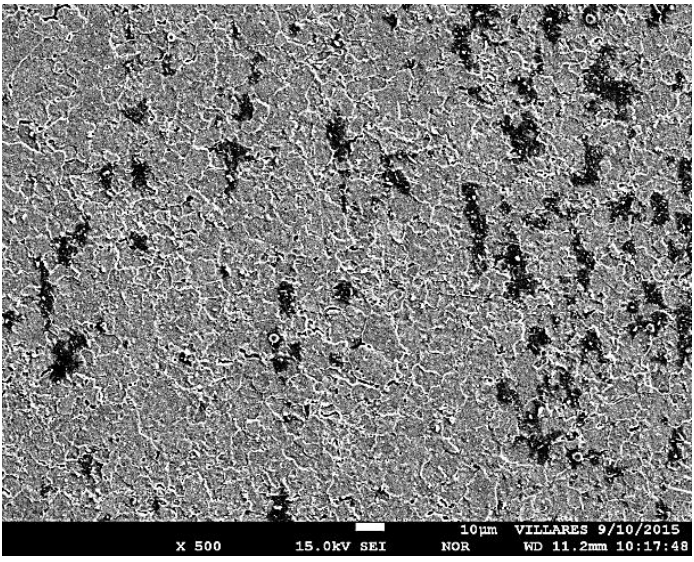

(b)

(a)

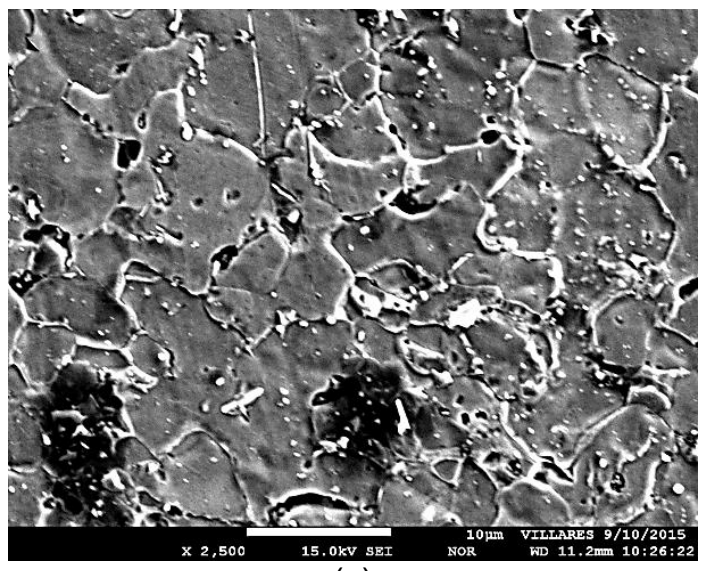

(c)

Figura 2. Parâmetro de soldagem I. (a) Seção transversal da junta soldada obtida por microscopia ótica após ataque com o reagente Adler. (b) e (c) Micrografias da zona de mistura obtidas por MEV em elétrons secundários após ataque metalográfico com o reagente Glicerégia.

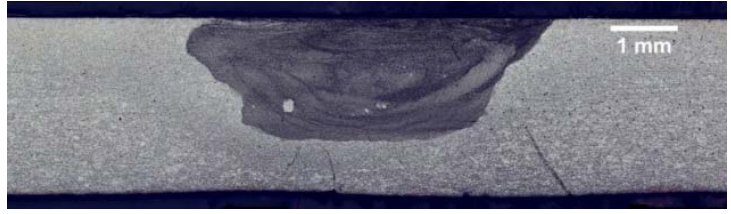

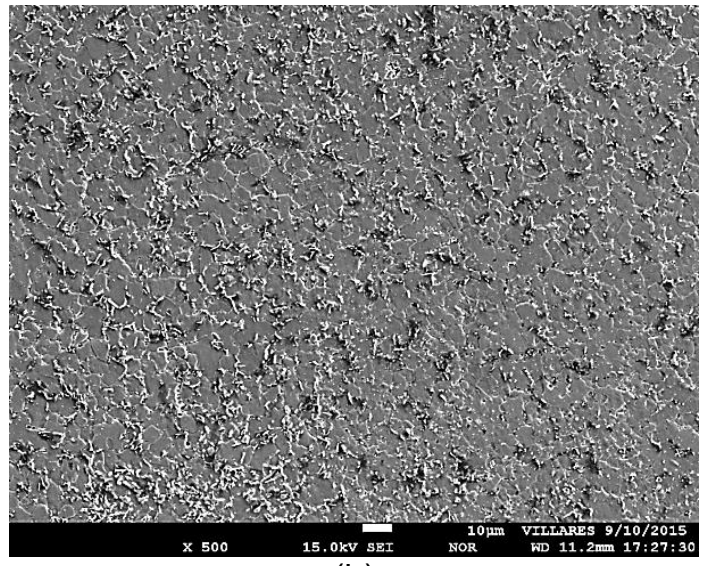

(b)

(a)

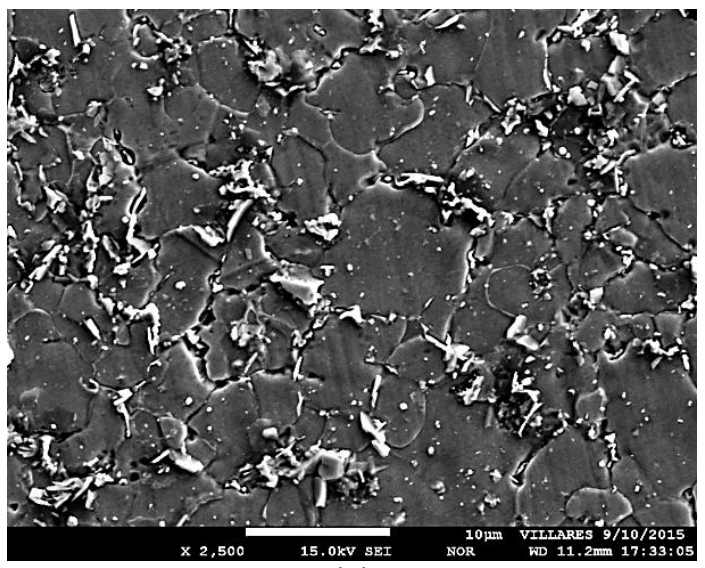

(c)

Figura 3. Parâmetro de soldagem II. (a) Seção transversal da junta soldada obtida por microscopia ótica após ataque com o reagente Adler. (b) e (c) Micrografias da zona de mistura obtidas por MEV em elétrons secundários após ataque metalográfico com o reagente Glicerégia.

Nas Figuras 4 e 5 observa-se que o menor aporte térmico (parâmetro IV) apresentou maior refino de grão quando comparado à condição com aporte térmico intermediário (parâmetro III). Durante o processo de soldagem a recristalização do 
material com as condições do parâmetro IV promoveram uma maior deformação do material que resultou em uma recristalização efetiva e, consequentemente, menor tamanho de grão.

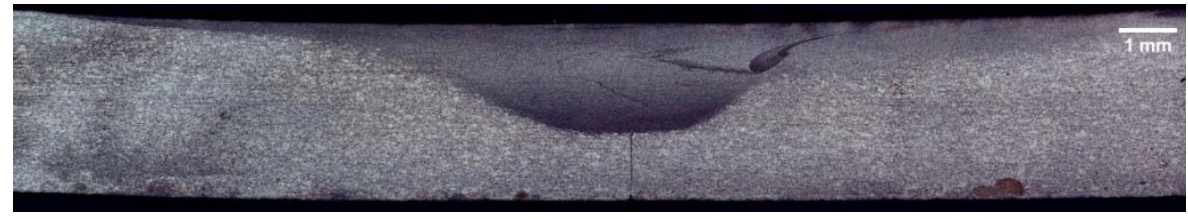

(a)

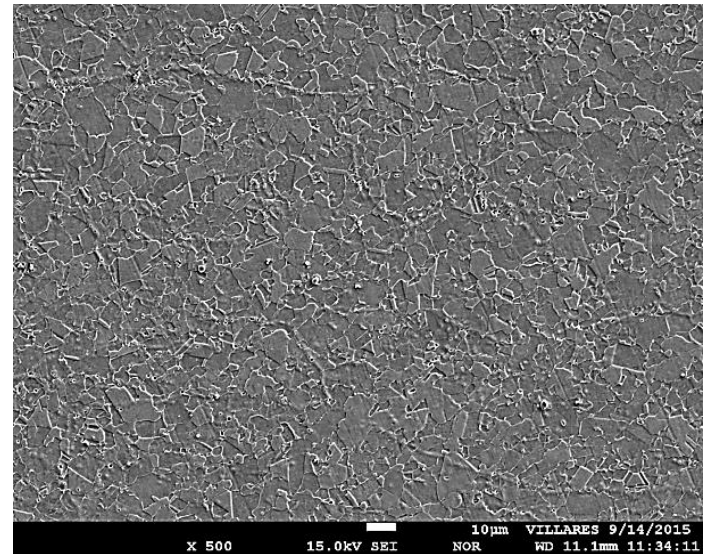

(b)

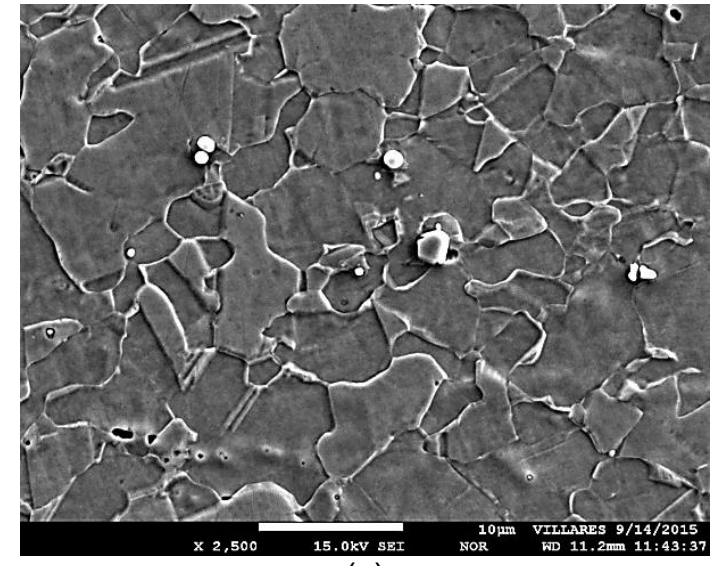

(c)

Figura 4. Parâmetro de soldagem III. (a) Seção transversal da junta soldada obtida por microscopia ótica após ataque com o reagente Adler. (b) e (c) Micrografias da zona de mistura obtidas por MEV em elétrons secundários após ataque metalográfico com o reagente Glicerégia.

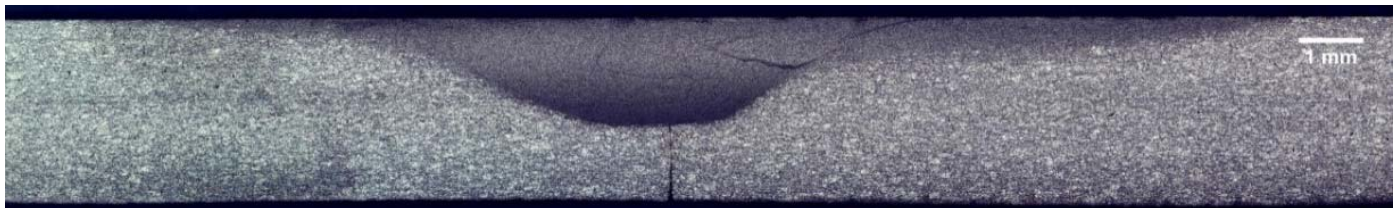

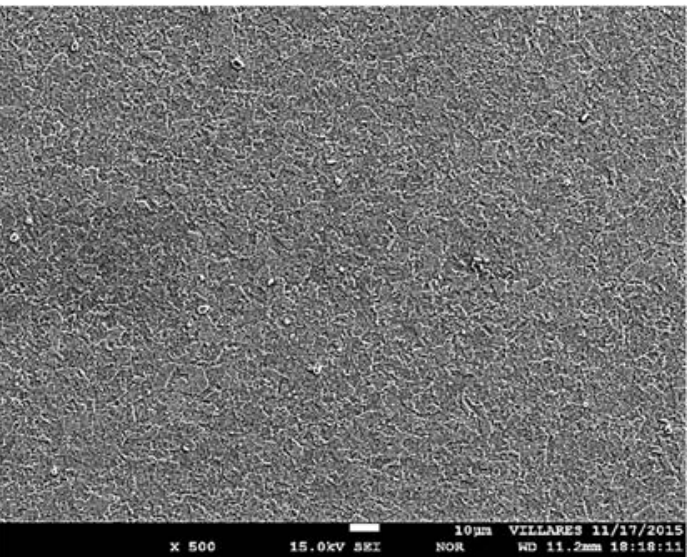

(b)

(a)

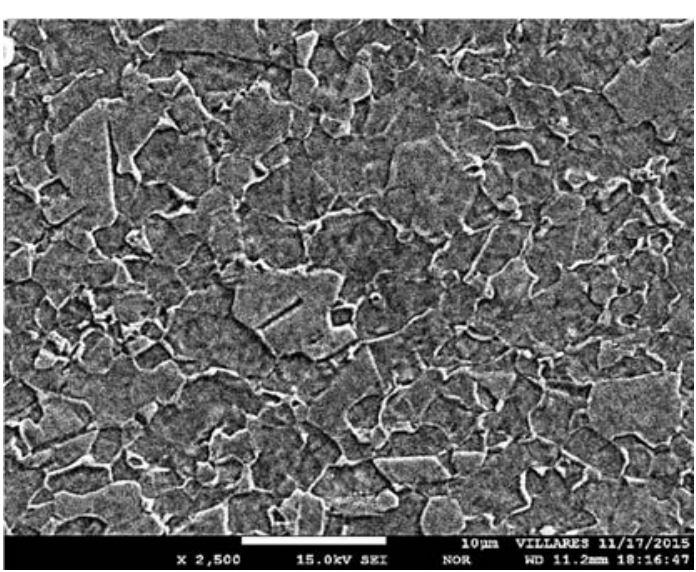

(c)

Figura 5. Parâmetro de soldagem IV. (a) Seção transversal da junta soldada obtida por microscopia ótica após ataque com o reagente Adler. (b) e (c) Micrografias da zona de mistura obtidas por MEV em elétrons secundários após ataque metalográfico com o reagente Glicerégia.

Comparando-se os resultados dos parâmetros I, II, III e IV, observa-se que aportes térmicos maiores que $2,30 \mathrm{~kJ} / \mathrm{mm}$ resultaram na ocorrência de porosidades no cordão de solda e presença de precipitados. Com relação aos parâmetros $/$ e II, pode-se concluir que a energia empregada foi elevada e ocasionou a presença de 
precipitados. Para as condições com menor aporte térmico (III e IV), a microestrutura mostrou-se limpa de precipitados, elevada qualidade do cordão de solda e microestruturas muito refinadas em relação ao metal de base. Como o mecanismo principal de endurecimento da liga 625 é através do refino do tamanho de grão [13], pode-se inferir que os parâmetros III e IV apresentam ótima resistência mecânica e, provavelmente, uma maior resistência à corrosão quando comparados ao material de base.

\subsection{Microdureza}

Os perfis de microdureza obtidos a $1 \mathrm{~mm}$ de distância da superfície de topo das juntas soldadas são apresentados na Figura 6. Todas as soldas indicaram um aumento de microdureza na junta soldada, resultante principalmente da redução do tamanho de grão. Como a largura do cordão de solda foi menor para os parâmetros I e II (Figuras 2 e 3 ) os perfis de microdureza foram medidos com distâncias menores. Em contraste, a largura do cordão de solda dos parâmetros III e IV foi maior (Figuras 4 e 5) e, assim, uma distância maior foi avaliada. Estas observações são coerentes com os resultados metalográficos apresentados (Figuras 1 a 5).

O material de base apresentou valores entre 243 a $275 \mathrm{HV}$. A chapa soldada com maior aporte térmico (parâmetro I) alcançou os menores valores de microdureza (270-305HV) ao longo do cordão de solda devido ao excessivo aporte térmico. De modo similar [2], este fato já foi reportado na literatura. No caso da junta soldada correspondente ao parâmetro II, apesar do elevado aporte térmico, foram alcançados os maiores valores de microdureza (na faixa de 310 a $347 \mathrm{HV}$ ). Além disso, os parâmetros I e II apresentaram maiores variações de microdureza entre o material de base e a junta soldada. A chapa soldada com aporte térmico intermediário, mas melhor aparência superficial (parâmetro III) apresentou valores de microdureza em torno de $300 \mathrm{HV}$ na região da solda. Ainda, as chapas com menor aporte térmico apresentaram um menor gradiente de microdureza em função da distância. Por último, a junta soldada chamada de parâmetro IV mostrou um comportamento similar à junta soldada de parâmetro III.

Comparando-se os resultados obtidos das medidas de dureza com a microestrutura verifica-se que a presença de precipitados para os parâmetros I e II aumentou localmente a dureza dos cordões de solda. Os resultados dos parâmetros de soldagem III e IV indicam que os maiores ganhos em termos de resistência mecânica na liga 625 são para a redução no tamanho de grão e não através de precipitação, isto é, de forma geral, a liga 625 apresentará melhor resistência mecânica e à corrosão quanto menor for o tamanho de grão e mais limpa for sua microestrutura, o que favorece sua aplicação com a condição Grau 2 da norma ASTM B446 desde que seu tamanho de grão esteja o mais fino possível [13]. 

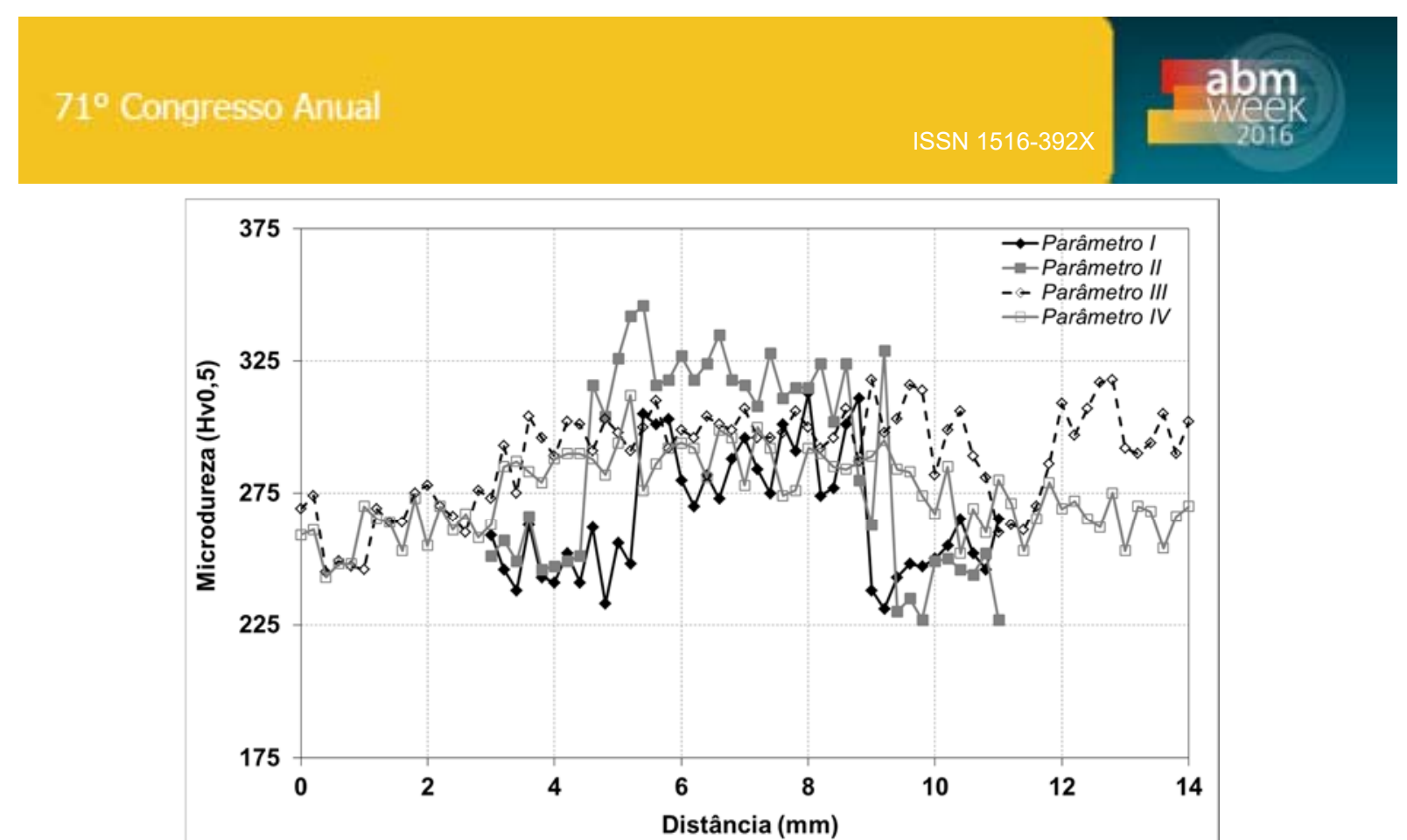

Figura 6. Perfis de microdureza para todas as juntas soldadas da liga 625 produzidas pelo processo SFMM.

\section{CONCLUSÕES}

Com base nos resultados obtidos no presente trabalho, é possível concluir-se que:

- As juntas soldadas que alcançaram maiores aportes térmicos, logo velocidades de rotação maiores (1200 e 1000 rpm), obtiveram menor largura do cordão de solda na seção transversal. Por outro lado, as juntas soldadas que apresentaram menor aporte térmico, por consequência das menores velocidades de rotação $(200 \mathrm{rpm})$, resultaram em uma largura maior do cordão de solda.

- Aportes térmicos menores que $2,30 \mathrm{~kJ} / \mathrm{mm}$ são aconselháveis para obtenção de uma microestrutura limpa e isenta de porosidades para a zona de mistura justificando, portanto, a observação da melhor qualidade do cordão de solda do parâmetro III.

- As medições de microdureza mostraram que o processo de soldagem por friç̧ão e mistura mecânica foi efetivo para a liga 625 ocasionando refino de grão e aumento de dureza para as juntas soldadas. No entanto, notou-se que altos aportes térmicos podem resultar em valores de microdureza ainda maiores, fato que pode estar ligado às características da superliga de Níquel.

\section{Agradecimentos}

Os autores agradecem o Conselho Nacional de Desenvolvimento Científico e Tecnológico (CNPq) através do programa Ciência sem Fronteiras e CAPES, assim como o Instituto Helmholtz-Zentrum Geesthacht GmbH (Germany) pelo suporte para execução deste trabalho. 


\section{REFERÊNCIAS}

1. Pollock, T. M.; Tin, S. Nickel-based superalloys for advanced turbine engines: Chemistry, microstructure, and properties. J Propul Power. (2006) pp. 361-74.

2. Lemos, G. V. B.; Simoni, L.; Bergmann, L.; Souza, D ; Araujo, D. B.; Dos Santos, J. F.; Strohaecker, T. R.; Schroeder, R. M. Caracterização Preliminar da Microestrutura em Cordões de Solda da liga 625 produzidos através dos processos de SFMM e MIG. XLI Congresso Nacional De Soldagem, Salvador - Bahia. 2015.

3. Avery, R. E.; Tuthill, A. H. Guidelines for Welded Fabrication of Nickel Alloys for Corrosion Resistante Service. (1994) pp. 1-35

4. Sorensen, C. D.; Nelson, T. W. Friction stir welding of ferrous and nickel alloys. Friction stir welding and processing. (2007) pp.111-21.

5. Davis, J. R., ed. Corrosion of weldments. ASM International, 2006

6. Thomas, WM; Nicholas, Ed; Needham, JC; Murch, MG; Temple-Smith, P; Dawes,

CJ. Friction-Stir Butt Welding, GB Patent No. 9125978.8, International patent application No. PCT/GB92/02203, (1991).

7. Gibson, B.T.; Lammlein, D.H.; Prater, T.J.; Longhurst, W.R., Cox, C.D., Ballun, M.C.; Dharmaraj, K.J.; Cook, G.E.; Strauss, A.M., 2014. Friction stir welding: process, automation, and control. Journal of Manufacturing Processes, 16(1), pp.56-73.

8. Zucchi, F.; Trabanelli, G.; Grassi, V. Pitting and stress corrosion cracking resistance of friction stir welded AA 5083. Materials and Corrosion 52.11 (2001) pp. 853-859.

9. Peel, M.; Steuwer, A.; Preuss, M.; Withers, P.J. 2003. Microstructure, mechanical properties and residual stresses as a function of welding speed in aluminium AA5083 friction stir welds. Acta materialia, 51(16), pp.4791-4801

10. Gharacheh, M. A.; Kokabi, A. H.; Daneshi, G. H.; Sarrafi, S. R. "The influence of the ratio of "rotational speed/traverse speed" $(\omega / \mathrm{v})$ on mechanical properties of AZ31 friction stir welds" International Journal of Machine Tools \& Manufacture, Vol 46, 2006, pp.1983-1987. 11. Perrett, J.; Martin, J.; Peterson, J.; Steel, R.; Packer, S. Friction Stir Welding of Industrial Steels. Friction Stir Welding and Processing VI. (2011) pp. 65-72

12. Petzow. G, Metallographisches Atzen (Materialkundlich-technische Reihe). Gebruder Borntraeger Berlin - Stuttgart. 1976

13. Farina, A.B. Efeito do teor de ferro e do tratamento térmico na microestrutura e propriedades da liga UNS N06625. Tese de Doutorado, Universidade de São Paulo, 2014. $123 \mathrm{p}$.

14. Lienert, T.; Stellwag, Jr. W.; Lehman, L. editors. Comparison of heat inputs: Friction stir welding vs. arc welding. AWS conference; 2002.

15. Ferrer, L.; Pieraggi, B.; Uginet, J.F. Microstructural Evolution During the Thermomechanical Processing of Alloy 625. [A. do livro] E. A. Loria. Superalloys 718, 625 and Various Derivatives. s.I.: The Minerals, Metals and Materials Society, 1991, pp. 217-228. 16. ASTM International. ASTM Standard B446. Standard Specification for Nickel-ChromiumMolybdenum-Columbium Alloy (UNS N06625), Nickel-Chromium-Molybdenum-Silicon Alloy (UNS N06219), and Nickel-Chromium-Molybdenum-Tungsten Alloy (UNS N06650)* Rod and Bar. West Conshohocken, PA : s.n., 2008. DOI: 10.1520/B0446-03R08E01. 